\title{
Ensaio em defesa da leveza, do sensível e da sensibilidade na pesquisa em educação
}

\author{
Monique da Silva* \\ Valeska Maria Fortes de Oliveira**
}

Resumo: Tomamos de empréstimo de Ítalo Calvino (1990) a primeira das suas seis propostas para o próximo milênio, a leveza, para pensarmos a questão do sensível e da sensibilidade na investigação educativa. O que propomos é refletir sobre uma possível mudança de ponto de vista na pesquisa em educação, sobre outra ótima, com outros recursos e possibilidades, com a leveza como centro desta ação. A leveza que pouco tem nos caracterizado pode constituir-se num desafio, numa condição para pensar num olhar investigativo sensível, atento aquilo que é percebido por um observador que se dá o tempo para a experiência. Um tempo para a experimentação e para a experiência formadora é condição para o aprendizado ético-afetivo, numa perspectiva spinozana. Na aprendizagem do que nos constitui, compreendendo os nossos afetos, propomos pensar a pesquisa em educação na dimensão do sensível.

Palavras-chave: Leveza. Sensível. Pesquisa em educação. Aprendizado ético-estético. Sensibilidade.

\section{Essay on defense the lightness, of the sensible and sensibility in education research}

\footnotetext{
* Mestre em Educação pela Universidade Federal de Santa Maria (UFSM), Professora do Instituto Federal Farroupilha - Campus Alegrete. E-mail: moniquedasilva88@gmail.com

** Doutora em Educação pela Universidade Federal do Rio Grande do Sul, Professora Titular do Departamento de Fundamentos da Educação na Universidade Federal de Santa Maria (UFSM).E-mail: vfortesdeoliveira@, gmail.com
} 


\begin{abstract}
We Italo Calvino loan (1990) the first of its six proposals for the next millennium, lightness, to think the issue of sensitive and sensitivity in educational research. What we propose is to reflect on a possible change of perspective in educational research, on another great, with other features and possibilities, with lightness as the center of this action. The lightness that little has characterized us may be in a challenge in a condition to think of a sensitive investigative look, given what is perceived by an observer who takes the time to experience. A time for experimentation and the formative experience is a prerequisite for the ethical-emotional learning, a spinozana perspective. On learning of what constitutes us, including our emotions, we propose thinking educational research in the dimension of sensitive.
\end{abstract}

Keywords: Lightness. Sensible. Education research. Ethical-aesthetical. Sensibility.

\title{
Ensayo en defesa de la ligereza, lo sensible y la sensibilidad en la investigación en educación
}

Resumen: Hemos cogido prestado de Italo Calvino (1990), el primero de sus seis propuestas para el próximo milenio, la ligereza, a pensar el tema de la sensibilidad y la sensibilidad en la investigación educativa. Lo que proponemos es reflexionar sobre un posible cambio de perspectiva en la investigación educativa, en otro grande, con otras características y posibilidades, con ligereza como el centro de esta acción. La ligereza que poco nos ha caracterizado puede estar en un desafío en condiciones de pensar en un aspecto de investigación sensibles, teniendo en cuenta lo que se percibe por un observador que se toma el tiempo para experimentar. Un tiempo para la experimentación y la experiencia formativa es un requisito previo para el aprendizaje ético-emocional, una perspectiva spinozana. Al enterarse de lo que nos constituye, incluyendo nuestras emociones, se propone pensar la investigación educativa en la dimensión de la sensibilidade.

Palabras clave: Ligereza. Sensible. Investigación en la educación. Aprendizaje ético y estético. Sensibilidad.

\section{Imagens da leveza... o apanhador de desperdícios}

Uso a palavra para compor meus silêncios.

Não gosto das palavras fatigadas de informar. 
Dou mais respeito às que vivem de barriga no chão

Tipo água, terra, sapo.

Entendo bem o sotaque das águas

Dou respeito às coisas desimportantes

E aos seres desimportantes

Prezo insetos mais que aviões.

Prezo a velocidade das tartarugas

Mais que as dos mísseis.

Tenho em mim este atraso de nascença.

Eu fui aparelhado para gostar de passarinhos.

Tenho abundância de ser feliz, por isso,

Meu quintal é maior do que o mundo.

Sou um apanhador de desperdícios:

Amo os restos como as boas moscas.

Queria que minha voz tivesse um formato de canto.

Porque eu não sou da informática:

Eu sou da invencionática.

Só uso a palavra para compor os meus silêncios.

É com Manoel de Barros que começamos as imagens da leveza, inspiradas em Calvino (1990), na sua primeira proposta para o próximo milênio. Aliamo-nos a este para pensar em (des)construções e (des) aprendizagens necessárias, que temos mobilizado no ambiente educacional, especialmente, na cultura da investigação. Temos receio de usar o pretérito para mencionar uma prática de pesquisa que naturalizamos através da concepção de "coleta de dados", nos ambientes educacionais, na perspectiva de procurar mazelas, deficiências, obstáculos, para que a educação consiga atender à metanarrativa de livrar todos da ignorância e, ao mesmo tempo, emancipar e produzir cidadania.

Investigações em excesso já foram realizadas nos ambientes educacionais, considerando os contextos, as pessoas, como objetos de estudo, numa racionalidade técnica, desprezando intensidades da ordem da aprendizagem do sensível. Talvez tudo isso responda por que os ambientes investigados se tornam refratários e defensivos aos resultados e 
propostas das pesquisas que acabam por não auxiliar as pessoas envolvidas a transformarem suas realidades.

Apanhar desperdícios, prestar atenção às desimportâncias, às minúcias, deveria ser um desafio a uma ciência com leveza. A invencionática poderia nos proporcionar exercícios mais intensos de astúcia, como nos fala Bachelard (1986), referindo-se ao método como invenção, criação. Nesse sentido constitui-se o desafio que assumimos como uma rede sensível na pesquisa em educação, uma rede pelo sensível na pesquisa em educação. Uma rede de pesquisadores, onde nosso grupo de pesquisa, Grupo de Estudos e Pesquisas em Educação e Imaginário Social (GEPEIS), é convidado a inserir-se e a compartilhar. Ainda, para, de início, dizermos de nosso local de fala, torna-se necessário trazermos o imaginário a esta escrita,

E, para começar, por que imaginário? Seria preciso, sem dúvida, nesse festival, dizer algumas palavras sobre esta noção. Imaginário porque a história da humanidade é a história do imaginário humano e de suas obras. História e obras do imaginário radical, que surge a partir do momento em que há uma coletividade humana: imaginário social instituinte que cria a instituição em geral (a forma instituição) e as instituições particulares da sociedade considerada, imaginação radical do ser humano singular (CASTORIADIS, 2004, p. 127).

Assim, sob a ótica do imaginário, nosso tempo é o das complexidades, das racionalidades de diferentes ordens: instrumental, comunicativa, científica, conceitual. Tempo de ruptura com as fragmentações, os dualismos. Tempo da cisão do científico com o poético, do diurno com o noturno. É o tempo de um humano genérico. Tempo que coloca a necessidade de se integrar o humano consciente (concius) e não consciente (ignarus); o humano angustiado (contristatus), degradado (deponatur) e o racional (rationalis); o humano imaginário (phantasticum) (OLIVEIRA, 2011); humano corpo biográfico (corporis biograhica) e o humano afeto (affecare). 
Na produção de imagens para a constituição de uma rede sensível na pesquisa em educação, partilhamos o trajeto que construímos coletivamente no GEPEIS, completando, neste ano de 2015, seus vinte e dois anos de existência e experiência. Não se constituiu um novo paradigma, mas outros olhares para as questões educacionais. O imaginário é motor do processo de investigação e tem, para nossa caminhada, o sentido de exercitar atos de criação, experimentações criativas - eventos e encontros de compartilhamento de saberes e sensações - que nos implicam e movimentam para experiências formativas. Projetos que mobilizam as energias e corpos na sua potência mais criativa. O sentido de exercitar atos de criação por meio de uma postura científica, artística, conduzida pela curiosidade - pode-se dizer, por um urgente e renovado espírito científico -, como já dissera Bachelard, na perspectiva de que este espírito parta de novos pressupostos epistemológicos, exercendo-os numa atividade que é mais do que produção de conhecimento, é uma estética da criação.

Cuidando da noção de método científico, Bachelard (1987) o representa como a polidez do espírito científico. Mostra que a dificuldade não se concentra mais nesse debate da necessidade do método, mas na diversidade dos métodos, na especialização das disciplinas. Criativamente, indica que o método é verdadeiramente uma astúcia da aquisição, um estratagema necessário na fronteira do saber, em outras palavras, um método científico é aquilo que procura o perigo. Seguro de seu acervo, ele se aventura numa aquisição. A dúvida é a posteriori e não a priori como na lógica cartesiana. Temos feito esse exercício na escrita das dissertações e teses, temos (des)aprendido muito, e uma das muitas descobertas refere-se a sensibilidade de quem lê e escuta a pesquisa. $\mathrm{O}$ campo de pesquisa do imaginário desafia-nos a conhecer por vias distintas, lugares bem conhecidos, pouco conhecidos e desconhecidos, necessários de serem comunicados a pessoas não especializadas. Um desafio com muitas experimentações, avaliações e aprendizagens intensas. 


\section{Outro elogio à razão sensível... imagens de leveza na literatura}

Michel Mafessoli (1998), numa obra provocativa intitulada Elogio da razão sensível, propõe-nos decifrar o mundo a partir de outras lógicas que não a da estrita racionalização, mas de uma razão sensível, capaz de disparar as intuições, captando na efervescência do social, o imprevisível, o fluido. Nisso é preciso outro movimento de olhar, outra corporeidade, outra física. No intuito de apresentarmos imagens do que falamos, tomamos emprestada a clássica obra de Charles Lutwidge Dodgson, sob o pseudônimo de Lewis Carroll, Alice no país das maravilhas, escrita em 1865 e, inspiradas nos estudos do imaginário, fizemos uma leitura das aventuras de Alice e os desafios e surpresas do estar/ser na universidade.

Entrelaçamos literatura e teorizações, pois sentimo-nos provocadas pela leitura, leitura anima,

Em suma, é preciso confessar que existem dois tipos de leitura: a leitura em animus e a leitura em anima. Não sou o mesmo homem quando leio um livro de idéias, em que o animus deve ficar vigilante, pronto para a crítica, pronto para a réplica, ou um livro de poeta, em que as imagens devem ser recebidas numa espécie de acolhimento transcendental dos dons. Ah, para fazer eco a esse dom absoluto que é a imagem de poeta seria necessário que nossa anima pudesse escrever um hino de agradecimento!

O animus lê pouco; a anima, muito.

Não é raro o meu animus repreender-me por ler demais.

Ler, ler sempre, melíflua paixão da anima. Mas quando, depois de haver lido tudo, entregamo-nos à tarefa, com devaneios, de fazer um livro, o esforço cabe ao animus. É sempre um duro mister, esse de escrever um livro. Somos sempre tentados a limitar-nos a sonhar (BACHELARD, 1988, p. 61-62. Grifo do autor).

No âmbito do que temos defendido na academia, do movimento instituinte do qual o GEPEIS participa, a leitura anima anda ao lado da leitura animus, sem sobreposições, nem juízos de valor, na luta pela valorização 
da multiplicidade, da vida e do imaginário. Segundo Mafessoli (1998, p. 180), "a vida, ou os imaginários que ela suscita, devem ser tomados por aquilo que são, ficando claro que sua eficácia é real, e que esta é a única que nos importa a partir do momento em que desejamos levá-la a sério". A atenção se volta aos sentidos que circulam, os deslocamentos de sentidos e, talvez, ao movimento do não sentido ou do sem sentido, mas uma outra lógica fusional do simples estar-junto.

A história de Lewis Carroll nos auxilia a olhar a partir do lugar que o imaginário habita na universidade e, com isso, perceber outras possibilidades de pensar as vivências com as quais nos deparamos na academia. Busca, curiosidade, experimentações, metodologia, surpresas, dúvidas, crises, exigências, tempo, aprendizagens e imaginação são alguns aspectos que trataremos neste texto sob a ótica de Mafessoli (1998), Castoriadis (2004; 1982) e Bachelard (1988).

Iniciando pela busca e curiosidade, nos movimentamos a partir de algo que nos inquieta, incomoda, faz-nos levantar da sombra confortável das grandes árvores e correr atrás dos tantos coelhos brancos que passam e afetam. A busca é um desejo interno, um movimento único e, ao mesmo tempo, provocador de interferências no meio, pois a mobilização de um sempre envolverá o outro, eis a importância das relações. Em Alice no país das maravilhas, a menina já começava a sentir-se cansada quando, de súbito, um Coelho Branco de olhos rosados passou por ela, a correr, de início não achou isso tão inusitado, mas,

No preciso momento em que o Coelho tirou um relógio do bolso do colete, olhou para ele e começou a correr mais depressa. Alice pôs-se em pé de um pulo, pois lembrou-se que nunca vira um coelho de colete nem de relógio. Ardendo de curiosidade, começou a correr: pelo campo, atrás dele, felizmente mesmo a tempo de o ver desaparecer no interior de uma grande toca que havia debaixo da sebe. No mesmo instante, Alice desceu atrás dele, sem pensar sequer como poderia voltar a sair. Lá dentro, a princípio, o caminho era a direito, como um túnel, mas depois, de repente, havia uma descida tão pronunciada que 
Alice nem teve tempo de pensar em parar senão quando deu consigo a cair num poço muito fundo (CARROLL, 1972, p. 7).

Como no livro, na pesquisa, na construção do conhecimento, no ingresso na carreira acadêmica, os inícios são como um salto no escuro, uma busca as tontas, imprevisível e, ao mesmo tempo, incontrolável. A busca por respostas, por esclarecimentos, conhecimentos e verdades - até aqueles que têm consciência da efemeridade da verdade são provocados a buscá-la. Assim, a partir do pulo somos levados às experimentações, ao novo, eis outro desafio.

Os livros, as pesquisas empíricas, os seminários, os outros, o ensino, a pesquisa, a extensão, inúmeras vivências e relações que nos atravessam, partem ou ficam, colorem e trazem sabor ao universo das experimentações. Neste território crescemos e encolhemos a todo instante, amedrontados ou envoltos em uma nuvem de coragem seguimos - nem sempre em frente - rumo ao desconhecido.

$\mathrm{Na}$ verdade, tantas coisas extraordinárias se tinham passado recentemente que Alice começava a convencer-se de que poucas seriam as impossíveis de realizar. Tudo indicava que não valia a pena ficar à espera junto da pequena porta, por isso, Alice voltou para a mesa, na esperança de encontrar ali outra chave ou um livro de instruções para ensinar as pessoas a fecharem-se como se fossem telescópios, mas desta vez o que achou foi uma pequena garrafa ("que decerto não estava ali antes", pensou) que, à roda do gargalo, tinha um rótulo de papel, onde podia ler-se em letras grandes e maravilhosamente impressas: "Beba-me!" (CARROLL, 1972, p. 10-11).

$\mathrm{Na}$ obra, Alice, após muito tempo em queda, acha-se em uma sala cheia de portas, encontra uma chave minúscula em cima da mesa e aí inicia o "estica-encolhe" de suas experimentações. Na pesquisa também acontece de tal forma, quando já estamos em campo iniciamos as escolhas de teorias, metodologias, intercessores e nos experimentamos 
em diversas formas de fazer/ser pesquisador. Em nosso Grupo apostamos nas experimentações sensíveis, nos encontros, nas vivências e também em espaços de formação inicial e continuada de professores. Refletimos sobre tais vivências, pois a ênfase na matéria viva é, segundo Mafessoli (1998, p. 182), "uma garantia de pertinência e, eu ousaria dizer, de fecundidade científica". Ainda diz o mesmo autor:

Sempre é tempo de encontrar explicações causais para as coisas humanas; num primeiro momento é, sobretudo, necessário compreendê-las. E isso não pode ser feito a não ser que se esteja atento à força vital que as anima e permite que sejam aquilo que são. Retomando um termo emprestado a Jung ou a G. Durand, direi que a vivência é um arquétipo, talvez o arquétipo essencial, em torno do qual se estrutura toda socialidade (MAFESSOLI, 1998, p. 182).

A socialidade é um estar-junto, mas de tal forma que o contrato social não se restringe a elementos racionais, mas integram-no os aspectos passionais, ilógicos. A plenitude do cotidiano se encontra neste conservatório energético, sem o qual pouco ou nada se compreende da perduração do ser, tanto individual quanto social. Assim, para dar conta de uma hermenêutica do social, é preciso encontrar um modo operativo que permita ir além do domínio da abstração, passando para o da imaginação e do sentimento, aliando o inteligível ao sensível. É preciso encontrar maneiras de pesquisar, é preciso encontrar meios de sair, ou seguir, das inúmeras situações, como vivencia Alice, quando em companhia dos inúmeros bichos à beira do Lago de Lágrimas.

"O que eu ia dizer", prosseguiu o Ganso com voz ofendida, "era que nada melhor para nos secar do que uma corrida eleitoral." "E o que é uma corrida eleitoral?" perguntou Alice, não porque quisesse realmente saber, mas porque o Ganso fizera uma pausa, como se alguém devesse perguntar, mas ninguém parecia inclinado a dizer nada. "Ora", disse o Ganso, "a melhor maneira de explicar isso é fazer." (E como vocês talvez queiram experimentar essa tal corrida em algum dia de 
inverno, vou contar-lhes exatamente o que fez o Ganso.)

Primeiro demarcou a pista, traçando uma espécie de círculo ("a forma exata não importa muito", explicou ele), depois toda a turma foi colocada em fila ao longo da pista, aqui e acolá. Não havia nada de "Um, dois, três, já!", pois cada um começava a correr quando quisesse, e parava também quando quisesse, de modo que não era nada fácil saber quando a corrida terminava.

Todavia, depois de terem corrido por mais ou menos meia hora e estarem já quase secos de novo, o Ganso gritou de repente: "Acabou a corrida!" E todos se juntaram em torno dele, ofegantes, perguntando: "Mas quem ganhou?" O Ganso teve de refletir muito antes de responder a essa pergunta. Ficou por longo tempo com um dedo apoiado sobre a fronte (na mesma posição em que geralmente se vê retratado Shakespeare), enquanto todos esperavam em silêncio. Enfim, o Ganso falou: "todo mundo ganhou, e todos devem ser premiados" (CARROLL, 1972, p. 21-23).

Eis a relação entre metodologia e invenção, encontrar maneiras, utilizar-se do potencial humano de criação. Nas pesquisas no campo do imaginário, encontrar metodologias subtende-se criá-las, usar e abusar da bricolagem, brincar - com licença poética - de utilizar inúmeras abordagens de pesquisa sem pudor, mas lembrando-se do rigor. E então, entregar-se aos ventos da surpresa.

Trabalhar com experimentações, metodologias e surpresas nos remete a algumas vivências no Encontro Ouvindo Coisas, evento bianual que promovemos na universidade, mais especificamente em sua primeira edição. O GEPEIS, ao propor provocadores no local de palestrantes, rodas de conversas nas quais os presentes não apresentavam suas pesquisas de modo clássico - em seus cronometrados quinze minutos -, também ao aliar exposições de artes visuais, performances, jogos cênicos, declamação de poesias e diversos festejos no espaço de um Encontro acadêmico operou com o trio supracitado, sob a influência da razão sensível, do devaneio, do imaginário.

Porém, é preciso ter consciência que a opção pelos caminhos do 
sensível e da experimentação em alguns momentos podem nos levar a dúvidas e crises, situações que parecem sem sentido, caso não a encaramos como outras vias de raciocínio possíveis. De fato, em alguns momentos encontraremos, como Alice, algumas Lagartas - potentes encontros que nos inculcam novos desafios, por mais que não os percebamos assim num primeiro momento.

A Lagarta e Alice olharam-se por algum tempo em silêncio. Por fim, a Lagarta tirou o cachimbo da boca e dirigiu-se a Alice com voz lânguida e sonolenta: "Quem é você?" Não era um começo de conversa encorajador. Alice respondeu muito tímida: "Eu... já nem sei, minha senhora, nesse momento... Bem, eu sei quem eu era quando acordei esta manhã, mas acho que mudei tantas vezes desde então...” (CARROLL, 1972, p. 34).

Aqui, Castoriadis nos dá motivos para seguir ao refletir que

Pensar não é sair da caverna, nem substituir a incerteza das sombras pelos contornos nítidos das coisas mesas, a claridade vacilante de uma chama pela luz do verdadeiro Sol. É entrar no Labirinto [...]. É perder-se nas galerias que só existem porque, incansavelmente, nós as escavamos, girar em círculos no fundo de um beco sem saída cujo acesso fechou-se por trás de nossos passos - até que esta rotação abra, inexplicavelmente, fissuras praticáveis na parede ${ }^{1}$ (CASTORIADIS, 2004, p. 7).

É preciso ter coragem para ousar defender os movimentos instituintes na academia. É sabido que na história, a noção de imaginário foi ignorada, muitas vezes maltratada, o sensível na academia foi motivo de desprezo, rotulado de perfumaria e, os que se aventuravam em devaneios vistos como loucos da casa. E também que é normal nos depararmos com

$1 \quad$ Les carrefours du labyrinthe, Paris, Éd. du Seuil, 1978, p.7-8; reed. col. "Points Essais", 1988, p. 6. (Nota do autor) 
Gatos Careteiros, Duquesas e Rainhas de Copas, porém, aos movidos pelos devaneios, tais fatores tornam-se pouco relevantes frente a alegria estética de poetizar na academia.

Títulos, conceitos, currículos, plataformas, financiamentos, exigências como no jogo de croquet da Rainha de Copas, todos tem seus respectivos lugares e quem deles sai ouvirá um sonoro "Cortem a cabeça!". A princípio, parece-nos que quem ousar descontentar a Rainha, ou não entrar em sua lógica, acabará impossibilitado de jogar - e isso muitas vezes acontece. Porém, no território da academia, é possível habitar ilhas sensíveis, construir fortes imaginários e, entre os pares, sobreviver. Como nos diz Bachelard (1988, p. 25) "Os poetas sempre imaginarão mais rápido que aqueles que os observam imaginar".

Também, para não sermos engolidos pela academia, é preciso relacionar-se com o tempo, saber sua importância, e esta lição nós - juntamente com Alice - ouvimos pela voz do Chapeleiro.

"Se você conhecesse o Tempo tão bem quanto eu conheço", disse o Chapeleiro, "você não falaria em gastá-lo, como uma coisa. Ele é alguém." "Não sei o que você quer dizer", disse Alice. "É claro que você não sabe!" disse o Chapeleiro, inclinando a cabeça com desdém. "Eu diria até mesmo que você nunca falou com o Tempo!"

"Talvez não", respondeu Alice com cautela, "mas sei que devo marcar o tempo quando aprendo música." "Ah! Isso explica tudo!" disse o Chapeleiro. "Ele não suporta ser marcado. Agora, se você mantivesse com ele boas relações, ele faria qualquer coisa que você quisesse com o relógio. Por exemplo, suponha que fossem nove horas da manhã, justamente a hora de começarem as lições: você teria apenas de sussurrar uma dica ao Tempo, e o ponteiro giraria num piscar de olhos: uma e meia, hora do almoço!” (CARROLL, 1972, p. 52-54).

O tempo é algo definidor, na academia e fora dela, para que possamos cumprir as exigências, vivenciar as experimentações e, ao mesmo tempo, cultivar relações e afetos. Castoriadis (1982, p. 147) percebe-o como uma instituição imaginária criada para que possamos suprir a necessidade 
de mensurar os períodos. Para ele existem dois tempos, o identitário da significação, do sensível, e o imaginário aquele cronológico, dos anos, das horas, do relógio. Para ele, em coro ao exemplificado pelo Chapeleiro "as articulações do tempo imaginário dobram ou aumentam os marcos numéricos do tempo calendário".

Associando as inúmeras relações apresentadas, com a força das vivências, chegamos as possíveis aprendizagens do fazer pesquisa na academia, do estar/ser estar neste território. Salientamos as aprendizagens e suas múltiplas facetas, com as cores e cheiros do experienciado, do sentido, do sonhado. Como aponta Mafessoli,

Sabendo integrar, de um ponto de vista epistemológico, a experiência sensível espontânea que é a marca da vida cotidiana, a progressão intelectual poderá, assim, reencontrar a interação da sensibilidade e da espiritualidade, própria, por exemplo, ao barroco, e assim alcançar, através da aparência, a profundidade das maneiras de ser e dos modos de vida pós-modernos que, de múltiplas maneiras, põem em jogo estados emocionais e "apetites" passionais que repousam, largamente, sobre a iluminação dos sentidos (MAFESSOLI, 1998, p. 196-197).

Entretanto, chegando ao fim do passeio pela obra de Lewis Carroll, apontamos a imaginação como elemento importante da criação humana. Aquela que auxilia na instituição do outro, que alia-se ao imaginário na construção outras formas de ver, na abertura de espaços de compartilhamento, na vivência de experiências sensíveis e, em especial, na valorização do sonho e do devaneio como instancias potentes - e possíveis. Como diria Alice eis em que dá o "curiosismo"!

\section{Imagens da leveza na empiria... a sensibilidade e o sensível nos movimentos de corpos biográficos}

Poderíamos talvez compreender, como resultado de pesquisas já realizadas com uma empiria que envolveu participantes do GEPEIS de 
diferentes momentos e épocas, e, através das narrativas, o acesso a uma continuidade discursiva sobre a intensidade do estar-junto afetivo para além da tarefa, comum na constituição de grupos. Mas, intuímos outra possibilidade nesta rede complexa que é o corpo-grupo. Conversando, ainda, com a produção de Spinoza (2009) e, talvez, aproveitando sua provocação sobre o que pode um corpo, pensamos o que podem corpos que experimentam olhar para suas biografias e perceber quais outros que aumentam, diminuem ou obstaculizam suas potências.

Nos diferentes experimentos que fazemos em grupo, quando cada pesquisador aponta para um Sobre Si na pesquisa, seja por objetos que escolhem para reconstruir imagens que produzem felicidade ou tristeza, desassossego ou tranquilidade, seja pela fotografia que aguça suas percepções, seja no jogo corporal, tudo faz de cada um dos corpos sensíveis - receptivos e ativos - que pensam suas produções como corpos biográficos, compreendidos como "história passada, presente e futura, através das sensações, das imagens, das visões animadas - espécies de sonhos acordados - das reminiscências, mas também das ideias e das escolhas" (JOSSO, 2012, p. 27).

Nossos corpos pesquisados-pesquisadores trazem/falam de trajetos, escolhas, energias, faltas, ausências, imagens de estados imaginários. É também nesse espaço grupal, como dispositivo de formação, que corpos biográficos, entendidos como a matéria onde ficam impressas as memórias do ser humano decorrente das suas experiências vividas, se encontram e potencializam energias, negativa ou positivamente, tomando aqui a reflexão de Spinoza (2009) sobre os estímulos emocionalmente competentes.

Talvez, sensivelmente, fomos desenvolvendo experimentos corporais em todos os ambientes educacionais onde o grupo foi convidado a compartilhar saberes, produzindo, muitas vezes, experiências formativas, percebendo a potência desta provocação como uma entrada sensível para a pesquisa/formação com professores.

O sensível é, segundo Didier Austry, 
o que se dá na experiência, sob forma de conteúdos de vivências específicos, em ligação com a animação interna. E: a fibra sensível do corpo [...], representa primeiramente sua capacidade de ser tocado, sua capacidade de responder, e seu potencial de evolutividade autônoma. O sensível é, portanto, o corpo que se desenvolve e atualiza a sua sensibilidade potencial além mesmo das capacidades de percepção habituais do sujeito (AUSTRY, 2008, p. 140).

Acrescentamos, na questão do corpo, desenvolver a sua sensibilidade potencial à experimentação que o grupo pode acionar, pensado como um dispositivo de formação/autoformação - dispositivos entendidos por nós como suportes ou condições de formação (FERRY, 2004). A educação, enquanto vivência estética, passa pela arte de experimentar outras formas de vida e de produção de outros sentidos e significados, para além dos já conhecidos e pertencentes ao seu trajeto de vida. Corpos biográficos são implicados para que se experimentem, olhando seus próprios trajetos e deixando-se atravessar por outros vetores, por outros movimentos e por outras subjetividades, ampliando seus repertórios. A subjetividade corporal ultrapassa a vontade intelectual de compreender e é via de acesso ao corpo biográfico.

$\mathrm{O}$ acesso a esse corpo falante de minha história passada, presente e futura (através das sensações, das imagens, das visões animadas - espécies de sonhos acordados - das reminiscências, mas também das ideias e das escolhas que se impõem de repente com evidência e graças à atenção consciente" (JOSSO, 2012, p. 27).

A processualidade dos encontros entre os corpos na concepção de Spinoza (2009) coloca-os em um plano onde não se buscam origens, afastando-se de transcendentais e das causas primeiras. $\mathrm{O}$ corpo pensado não é algo fechado, pois afeta e é afetado produzindo encontros de composição e decomposição, bons ou maus encontros, que aumentam ou diminuem a potência do corpo - a nossa potência. 
Pensar imagens da leveza na empiria dos processos formativos e investigativos com Spinoza e a potência da sua produção, deslocando o aprender e o conhecer para outra fonte, merece uma contextualização também da intensidade do seu pensamento. Ao pensar prazer e dor na ciência dos sentimentos, Damásio retrata-o um fermento de interrogações.

Trata-se de uma época intelectualmente fértil. Mais ou menos na época do nascimento de Espinosa, Thomas Hobbes e Descartes cresciam como estrelas filosóficas e William Harvey apresentava a sua descrição da circulação sanguínea. Durante a vida breve de Espinosa, o mundo conheceria o trabalho de Blaise Pascal, Johannes Kepler, Huygens, Gottfried Leibniz e Issac Newton, que nasceu apenas dez anos mais tarde que Espinosa (DAMÁSIO, 2004, p. 237).

Considerado "o mais intolerável dos iconoclastas" (DAMÁSIO, 2004, p. 238), Spinoza colocou em questão os alicerces da religião e as estruturas políticas relacionadas a esta. Contemporâneo de Kant, ele chamou atenção para os perigos da paixão - Spinoza apresenta uma racionalidade que necessita da emoção como motor. A emoção como o motor que aciona o afeto com um aprendizado por excelência. Um aprender que envolve também pensar nossos afetos, ligados a nossa potência de afetar e ser afetados. A noção de afeto por ele desenvolvida remete a outra noção importante na sua produção - a de encontro.

Compartilhamos com Merçon (2009, p. 28), quando se refere a um aprendizado afetivo referenciado num devir ético: "A noção de afeto remete-nos, assim, à noção de encontro. Pensaremos o aprendizado afetivo como uma arte de encontro: um aprender sobre o que diminui nossas forças ou nos potencializa". O aprendizado afetivo corresponderia a um processo de ativação do nosso desejo. Ativaria afetos alegres e afetos tristes.

Ainda cabe compreender a noção de corpo spinozano, diferentemente das concepções mecanicistas ou organicistas que não associam o corpo aos afetos. Como um corpo afetivo, Spinoza (2009) também o 
propõe como corpo relacional, em que outros participam da composição de um corpo.

Mesmo não se tratando de um ensaio sobre as concepções de Spinoza, pensamos oportuno salientar algumas noções fundamentais para a compreensão do seu pensamento e da radicalidade das suas proposições. Assim, por exemplo, temos a noção de substância.

Enquanto para Descartes corpo e mente são substâncias distintas que interagem uma com (e contra) a outra, para Spinoza, corpo e mente são modos que pertencem a uma mesma substância e que, embora, distintos um do outro, não se relacionam causalmente. Em oposição à regra cartesiana da relação inversa (segundo a qual a ação da alma equivale ao padecer do corpo e vice-versa), encontramos em Spinoza a tese do paralelismo corpo-mente, ou seja, uma espécie de correspondência ou isonomia entre os dois modos ou atributos (MERÇON, 2009, p. 39).

O aprendizado ético-afetivo pelo corpo que somos, e pelo corpo que podemos vir a ser, pela nossa potência e pelos afetos que passam a ser mobilizadores de outras energias - tristes ou alegres - que aumentam ou diminuem nossa potência, é uma das possíveis respostas para a vida longa de um grupo que quando imerso em projetos de formação / investigação com outros professores consegue mobilizar afetos alegres que geram mais potência ao corpo-grupo e ao corpo-pessoa. Ao contextualizar a questão spinozana $O$ que pode um corpo?, Merçon (2009) explicita:

O que ele pode corresponde à sua capacidade de afetar e ser afetado, sendo esta necessária e constantemente exercida em suas relações com outros corpos. Podemos dizer assim que cada corpo exerce, a cada momento, toda a sua potência. Porém, em outro sentido, podemos também dizer que a capacidade de um corpo de ser afetado pode ser exercida de maneiras que aumentam sua potência ou que a diminuam ou a obstruam de tudo aquilo que pode (MERÇON, 2009, p. 43). 
O que pode um corpo quando soma-se a outros que potencializam afetos alegres movimenta meu pensamento para uma ideia - o corpogrupo pode quando através de ações produz encontros com outros corpos e avalia aqueles que potencializam mais energia e afetos alegres ou que despotencializam por afetos tristes.

Gestar um grupo que tem o imaginário e as dimensões simbólicas como foco de estudos e pesquisas exige das pessoas que integram e que exercitam um lugar de coordenação, outros olhares, outras escutas e inserções. Um olhar e uma escuta que se deixam surpreender, sem um dever-ser. O olhar mirado é um olhar adjetivado não é qualquer olhar, é um olhar sensível, erótico, afetual. Na experiência do GEPEIS, temos reflexões como esta "desse lugar de gestora, imbuída por uma razão sensível (MAFFESOLI, 1998) na perspectiva de dar evidência ao testemunho da aprendizagem da pesquisa coletiva e ao registro denso do estar-junto, permito-me surpreender-me com o que se mostra, com os encontros". ${ }^{2}$

O registro denso do estar-junto a partir de uma razão sensível é na pesquisa o exercício para que na leitura do contexto, do grupo, do ambiente, do instituído e do instituinte, numa lente simbólica, tenhamos os indícios. Os indícios estão relacionados a investigações que partem do caráter micro no âmbito do político, do social e do cotidiano. Uma prática interpretativa interdisciplinar que coloca ao investigador a exigência de razão e sensibilidade, de imaginação e criatividade. Os indícios são as fontes, mas não quaisquer fontes, são as que muitos pesquisadores não percebem num primeiro momento, quando não suspendem suas hipóteses e teorias sobre o que estão a pesquisar. Penso que talvez um dos mais complexos exercícios na pesquisa, é a sensibilidade de deixar vozes, movimentos, acontecimentos, minúcias terem visibilidade e, talvez, voz e ação na condução da investigação.

Indícios são fontes perceptíveis para um pesquisador sensível e atento. Aquele que se dá o tempo para estar atento. Que não procura apenas

2 Fala de uma das autoras deste artigo e coordenadora do grupo de pesquisa. 
levantar dados a partir do que se mostra, mas especialmente daquilo que não está à mostra. Indícios podem estar nos silêncios, nas brechas; por isso, a sensibilidade na escuta e na observação são ingredientes que dão sabor à atividade de pesquisa.

Essa é uma aprendizagem ético-afetiva que temos mobilizado como grupo. Contando nossas histórias nos (re)apresentamos e também nos constituímos pesquisadores de nós mesmos, porque juntamente com o processo de entendimento do imaginário construído social, política e historicamente sobre nossa profissão e a figura do professor, desejamos compreender como nos tornamos o que somos. O que fazemos com o que fizemos do que fizeram de nós e do que podemos ainda ser.

O corpo-grupo pensado a partir do movimento que produz a interrogação e a reflexão, como um dispositivo de formação, tem provocado seus participantes a contar suas histórias, seus trajetos de vida. Nesta perspectiva, Momberger (2008, p. 35) mostra a relação estreita entre formação e biografização da vida das pessoas que se colocam como contadoras de histórias, onde podem se apropriar dos seus repertórios, dos seus trajetos vividos. O ser humano apropria-se de sua vida e de si mesmo por meio de histórias. Antes de dar existência às suas histórias para comunicá-las aos outros, o que cada um vive só se torna sua vida se há um Si que não escapa mais às figurações que representam a sua existência.

É com esta visão que realizamos pesquisa e extensão, com outros professores de escolas e contextos diferenciados de formação, implicando-nos nas experimentações. Fazemos do processo uma experiência, primeiramente para os pesquisadores e, posteriormente, para aqueles que são convidados a implicarem-se com os dispositivos que propomos. Uma relação da palavra binômio formação/investigação com o tempo. Um tempo que, para os estudos e pesquisas que nosso grupo tem realizado, encontra seu lugar, seu território, na memória. Formação que extrapola o tempo presente, já tendo sido experienciada no passado e através do trabalho da memória é reconstruída, inventada, ficcionada, esquecida. 


\section{Relatos-histórias aconchegantes... experiências a partir de uma ética do sensível, infinitas imagens}

Na imanência dos encontros de corpos não isolados, mas na sua potência grupal, tivemos, nestes vinte e dois anos, bons e maus encontros, produtores de aumento e também diminuição da nossa potência. $\mathrm{O}$ estar junto grupal aciona afetos alegres, mas, algumas vezes, afetos tristes, diminuidores da nossa potência grupal. A partir desta perspectiva, afetos tristes também são alimentos para os pensamentos dedicados a formação, pois assim como os afetos alegres, constituem os caminhos percorridos pelos corpos sendo, desta forma, necessário que não sejam descartados, mas sim considerados como parte das vidas, não como lixo a ser rejeitado, mas sim como potencia a ser transformada.

A investigação construída com uma escola da rede estadual de nosso município, a partir de um projeto de formação continuada atento aos saberes docentes já presentes na instituição, levou-nos, há seis anos, a uma pesquisa onde a escuta e o olhar sensível produziram indícios para o início de uma parceria. Encontro de corpos que aumentou suas potências, indicada, noutro texto propositivo de uma outra interlocução ético-afetiva, entre universidade e escola (OLIVEIRA, 2012). Outra interlocução, um novo contrato social entre universidade e escola. Um contrato que dá início à pesquisa-formação, partindo do princípio que acontecerá com os professores da escola e não sobre eles. Um encontro que reconhece e valoriza que a investigação e o processo formativo começam com a narrativa dos trajetos já vividos, dando visibilidade para anonimatos e falta de referências e de memória.

A leitura primeira, naquela experiência, foi a do ambiente cansado, desanimado, dividido e com poucos afetos alegres. A impressão que tivemos ao realizar a primeira reunião com a equipe diretiva foi a de afetos tristes, que despotencializavam a própria instituição, além das relações de poderes manifestas. Professores novos já falando de aposentadorias. Professores mais antigos contando os dias para a mesma. Muitos laudos 
médicos, falta de docentes e turmas sem professores. Ações isoladas de corpos sem afetos alegres. Reclamações, desesperanças e o já esperado: a culpabilização aos estudantes por não estudarem, não participarem, não lerem e, portanto, por nada acontecer. Escola com três turnos - três escolas com pessoas que não interagiam, não relacionavam-se, mas faziam parte da mesma Instituição.

A sensibilidade na organização do projeto pelo GEPEIS previa uma inserção no grupo da escola, convidado para realizar um projeto de formação conosco, uma vivência corporal. A vivência corporal como um dispositivo para um aquecimento e aproximação dos corpos - onde nos experimentamos mais soltos, mais lúdicos, mais afetuosos, mais humorados. Alguns menos animados, mas contagiados entravam e se divertiam. Esse aquecimento era para começarmos a pensar na nossa condição corpo - o que somos - o que trazemos na nossa história de vida - corpo biográfico (JOSSO, 2012) - os nossos limites, dificuldades e facilidades de expressão e de experimentação.

Encontros acontecendo - relações acontecendo - potências aumentando - diminuindo - aumentando - experimentações - novos projetos - a parceria intensificada - do agrupamento de pessoas à formação do grupo como dispositivo. Estas aprendizagens trazidas para o âmbito do grupo de pesquisa sensibilizaram nosso olhar para a continuidade do trabalho com a escola estadual, que no nosso entendimento, depois de três, já tinha construído possibilidades para a realização de suas ações reflexivas de forma autônoma. Mas a escola, já com outra coordenação - com características mediadoras e propositivas - apelou para a continuidade da nossa presença e, assim, quando todos os integrantes do GEPEIS chegaram para a reunião eu já havia sinalizado a continuidade. A sintonia e sensibilidade do grupo era tão grande que, somente ao olhar para o grupo, percebi que aprovavam minha decisão. ${ }^{3}$ E lá continuamos por mais um ano, mobilizando a construção coletiva de um projeto político-pedagógico, organizando e

3 Memória de uma das autoras deste artigo e coordenadora do grupo de pesquisa. 
participando junto com os professores do processo de envolvimento de toda a comunidade. Nossa alegria era tamanha, quando numa das reuniões, véspera de feriado na cidade, a participação era intensa dos pais, lotando o auditório de uma grande escola de ensino médio, vizinha desta.

Corpos que se encontram e potencializam outros - gerando mais potência - afetos alegres produtores de movimentos que nos levavam a ler sensível e simbolicamente desde a organização do espaço de reuniões, uma mesa circular em uma sala pintada de um azul acolhedor. Uma escola que se organizou para cumprir aquilo que tanto era perguntado quando passávamos nas salas de aula dos estudantes de todos os níveis - o que estamos levantando como a escola que temos e a que desejamos - vai ser levado em conta? Por quem? Ou ficará no papel? As salas foram pintadas, laboratório de informática climatizado. A escola tinha projetos que iam, aos poucos, sendo recuperados e intensificados. A escola passa a ir à Feira do Livro lançar obras coletivas dos estudantes, professores da escola começam a escrever livros com suas melhores experiências pedagógicas - A escola passa a ter, ao invés de laudos - lamentações por estar chegando o dia da aposentadoria, energias para outros projetos. (Res)significados os espaços, os lugares, o cotidiano escolar, outros sentidos para o trabalho e as noções de currículo - como experiências, como projetos interdisciplinares. Mais convivência para a organização destes projetos - afetos alegres - amizades para além da escola - mais projetos - corpos potentes - encontros produtores de alegria.

A leitura de todo esse cenário e estes atores e seus protagonismos exigiu uma leitura sensível onde fomos avaliando os corpos que diminuíam a potencia dos projetos que apresentavam-se como criações coletivas e os corpos que aumentavam a potência. A eles nos juntamos. Com eles nos afetamos. Com eles nos sensibilizamos.

Nesta caminhada, passamos de pesquisadores da universidade que vão até a escola, convidados para um projeto de formação que assume um formato também de investigação à realizadores de projetos conjuntos. Nossa pesquisa atual, com caráter também de projeto de extensão sobre 
tempos de formação e o cinema na vida do professor é uma proposição entre o grupo de pesquisa e a Escola Estadual para professores de outra rede, a de nosso município, narrada neste relato ético-afetivo. Somos corpos com afetos alegres tentando contagiar e ser contagiados por outras energias, descobrindo outras potências, capazes de aumentar as nossas. Nossas aprendizagens nestas experimentações através dos dispositivos propostos às escolas e aos professores são da (des)ordem da afetividade, da educação ético-estética (HERMANN, 2010) e da sensibilidade.

\section{Referências}

AUSTRY, Didier. O tocante-tocado na relação com o sensível - Por uma filosofia do contato. In: BOIS, Danis; JOSSO, Marie-Christine; HUMPICH, Marc. (Org.). Sujeito sensivel e renovação do eu. As contribuições da fasciaterapia e da somato-psicopedagogia. São Paulo: Paulus, 2008.

BACHELARD, Gaston. O novo espirito cientifico. Lisboa: Edições 70, 1986.

- A filosofia do não: filosofia do novo espírito científico. Lisboa: Presença, 1987. . A poética do devaneio. São Paulo: Martins Fontes, 1988.

BARROS, Manoel de. Poesia completa. São Paulo: Leya, 2010.

CALVINO, Italo. Seis propostas para o próximo milênio. São Paulo: Companhia das Letras, 1990.

CASTORIADIS, Cornelius. A instituição imaginária da sociedade. Rio de Janeiro: Paz e Terra, 1982.

. Figuras do pensável: as encruzilhadas do labirinto. v. 6. Rio de Janeiro: Civilização Brasileira, 2004. 
CARROLL, Lewis. Alice no país das maravilhas. São Paulo: Editora Abril Cultural, 1972.

DAMÁSIO, António. Em busca de Espinosa: prazer e dor na ciência dos sentimentos. São Paulo: Companhia das Letras, 2004.

FERRY, Gilles. Pedagogia de la formación. Buenos Aires: Centro de Publicaciones Educativas y Material Didáctico, 2004.

HERMANN, Nadja. Autocriação e horizonte comum. Ensaios sobre educação ético-estética. Ijuí: UNIJUÍ, 2010.

JOSSO, Marie-Christine. O corpo biográfico: corpo falado e corpo que fala. Educação e Realidade. Porto Alegre, v. 37, n. 1, p. 19-31, jan./abr. 2012.

MAFFESOLI, Michel. Elogio da razão sensivel. Petrópolis: Vozes, 1998.

MERÇON, Juliana. Aprendizado ético-afetivo. Uma leitura spinoziana da educação. Campinas: Alínea, 2009.

OLIVEIRA, Valeska Fortes de. Dispositivo grupal e formação docente. Educere et educare. Revista da Educação, v. 6, n.11, p. 125-140, jul./ dez. 2011.

. As interlocuções entre a pós-graduação e a educação básica, em tempos de reconstituição das relações ético-político-afetivas. In: RAMOS, Flávia Brocchetto; PAVIANI, Neires Maria Soldatelli; AZEVEDO, Tânia Maris de. (Org.). A pós-graduação e suas interlocuções com a educação básica: múltiplos olhares. [recurso eletrônico] Caxias do Sul: Educs, 2012.

SPINOZA, Benedictus de. Ética. Belo Horizonte: Autêntica Editora, 2009.

Data de registro: 30/07/2014

Data de aceite: 09/06/2015 